\title{
Subauroral polarization streams: observations with the Hokkaido and King Salmon SuperDARN radars and modeling
}

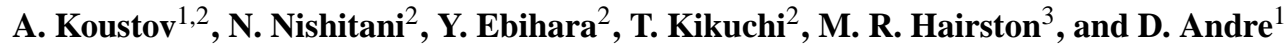 \\ ${ }^{1}$ Institute of Space and Atmospheric Studies, University of Saskatchewan, 116 Science Place, Saskatoon, S7N 5E2 Canada \\ ${ }^{2}$ Solar-Terrestrial Environment Laboratory, University of Nagoya, Nagoya, Japan \\ ${ }^{3}$ William B. Hanson Center for Space Sciences, University of Texas at Dallas, USA
}

Received: 28 April 2008 - Revised: 21 August 2008 - Accepted: 10 September 2008 - Published: 21 October 2008

\begin{abstract}
The newly installed SuperDARN Hokkaido HF radar monitors ionospheric plasma flow between magnetic latitudes of $45^{\circ}$ and $65^{\circ}$ and thus has a great potential for studies of subauroral polarization streams (SAPS) in combination with another SuperDARN radar located at King Salmon, Alaska as well as the DMSP satellites and groundbased instruments in the Alaskan sector of the Arctic. Preliminary survey shows that although SAPS are often detected with the Hokkaido radar, their velocities are rather low, to the order of $150 \mathrm{~m} / \mathrm{s}$ in its most suitable central beams. In this study, observations of unusually fast Hokkaido flows of up to $800 \mathrm{~m} / \mathrm{s}$ are presented. The event of 1 April 2007 is investigated in detail. It is shown that high-velocity echoes appear after substorm onsets over North America with a delay of $\sim 30 \mathrm{~min}$. In terms of latitude, the velocity peaks just outside the auroral oval; signatures of a detached polarization jet are occasional and not pronounced. The King Salmon radar operating concurrently detects SAPS signatures as well but at different times and locations. Simulation with the Comprehensive Ring Current Model for the 1 April event reasonably identifies the period of fast flow occurrence but the velocity is underestimated. The event studied suggests that substorminjected particle populations may intensify the pre-existing SAPS flow and lead to a mismatch of the predictions and observations.
\end{abstract}

Keywords. Ionosphere (Auroral ionosphere; Electric fields and currents) - Magnetospheric physics (Magnetosphereionosphere interactions)

\section{Introduction}

Super Dual Auroral Radar Network (SuperDARN) HF radars have been initially introduced to monitor plasma convection

Correspondence to: A. Koustov

(sasha.koustov@usask.ca) at high magnetic latitudes of $>65^{\circ}$ (Greenwald et al., 1995). Several recent publications have demonstrated that some of the SuperDARN radars can also be useful for studies of subauroral polarization streams (SAPS), which are fast flows at or equatorward of equatorial edge of the auroral oval (Parkinson et al., 2003, 2005; Koustov et al., 2006; Makarevich and Dyson, 2007). SAPS events have been identified and investigated for relatively low-disturbed magnetic conditions. Construction of new SuperDARN radars at Wallops Island (Oksavik et al., 2006) and on Hokkaido (Nishitani et al., 2005, 2007) at mid-latitudes has significantly improved the SuperDARN network capabilities in SAPS studies as these new radars monitor plasma flows at magnetic latitudes between $\sim 40^{\circ}$ and $65^{\circ}$, i.e. at all latitudes where SAPS flows are expected to occur (Foster and Vo, 2002).

Previous SuperDARN observations have demonstrated many SAPS features identified with other techniques. For example, direct measurements of flow velocities as high as $2 \mathrm{~km} / \mathrm{s}$ were reported by Koustov et al. (2006), which is consistent with satellite measurements of fast ion drifts at much larger heights (e.g. Anderson et al., 1991, 1993, 2001). Oksavik et al. (2006) showed an extreme variability of the velocity within the SAPS channel. This feature was first reported on the basis of indirect Millstone Hill observations by Foster et al. (2005). Makarevich and Dyson (2007) showed that SAPS flows can exist in a dormant state for a long time, for at least two substorm cycles, and they can be intensified by the substorm processes, in agreement with Anderson et al. (1993).

Some SuperDARN results, however, seem to disagree with previous reports. One area of controversy is the relationship between the SAPS occurrence and substorms. Parkinson et al. (2003) reported that SAPS flows are usually enhanced near substorm onset while Koustov et al. (2006) presented examples of flow enhancements with a delay of 3050 min from substorm onset. Makarevich and Dyson (2007) had cases of SAPS intensifications both prior to and after

Published by Copernicus Publications on behalf of the European Geosciences Union. 


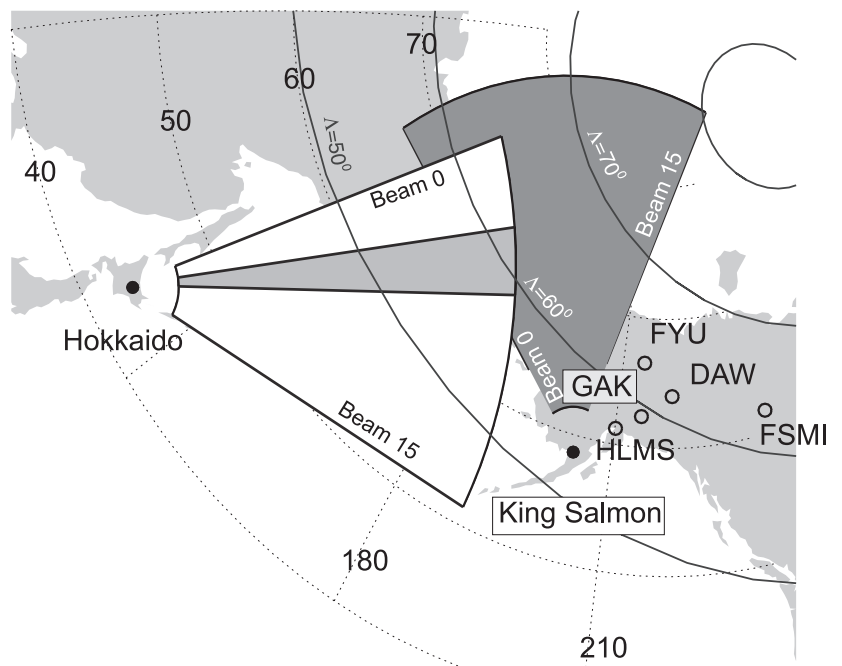

Fig. 1. Fields of view of the Hokkaido (between 400 and $3550 \mathrm{~km}$ ) and King Salmon (between 400 and $2800 \mathrm{~km}$ ) SuperDARN radars and locations of magnetometers in the Alaskan sector of the Arctic. Information on magnetometers is given in Table 1. The dark shaded sector within the Hokkaido field of view indicates the orientation of beams 4-6 statistics for which is presented in this study.

substorm onset. Parkinson et al. (2007) analyzed an event that was apparently not related to substorms at all. It well might be that the controversy is an apparent one as flows outside the auroral oval typically occur, and it is only a question whether one would be interested finding out the reasons for the occurrence of extreme velocities. This notion resonates with recent SuperDARN Hokkaido radar results on sheared SAPS flows at latitudes of $\sim 55^{\circ}-60^{\circ}$ (Kataoka et al., 2007). These flows were relatively slow $(<300 \mathrm{~m} / \mathrm{s})$. The authors claim that if the flow were along the magnetic L-shells, the velocity magnitudes would have been about 2 times larger. These are not exceptionally high velocities but observations did satisfy all currently accepted criteria of SAPS flows. Moreover, the location, occurrence time and velocity magnitudes were somewhat consistent with predictions of the Comprehensive Ring Current (CRC) model, that was described in detail by Fok et al. (2001) and Ebihara et al. (2004). One has to recall that the CRC model involves substorm processes only marginally (by including into the analysis the ion fluxes from the tail). Good agreement between the observations and the CRC model reported by Kataoka et al. (2007) might be interpreted as absence of substorm contribution to the SAPS intensity.

In this study we consider one unusually high-velocity SAPS event observed with the Hokkaido SuperDARN radar on 1 April 2007 with a goal to investigate its relationship with substorms. We combine the Hokkaido observations with measurements performed by the King Salmon SuperDARN radar in a nearby area, DMSP measurements over the radars field of view, and ground-based instruments in the Alaskan sector of the Arctic. The radar data are compared with the CRC model predictions of the SAPS onset time and intensity to assess, from one side, its performance, and, on the other side, to investigate the role of substorm processes in generation of SAPS.

\section{Geometry of observations and typical velocities of Hokkaido echoes}

Figure 1 shows the fields of view (FoV) of the Hokkaido (HOK) and King Salmon (KSR) SuperDARN radars. Ranges from 400 to $3550 \mathrm{~km}(2800 \mathrm{~km})$ were used for the HOK (KSR) radar. While the KSR radar monitors ionospheric plasma flows at magnetic latitudes of $\Lambda>60^{\circ}$ and predominantly along the L-shell direction, the HOK radar can potentially detect echoes at magnetic latitudes as low as $\Lambda \sim 40^{\circ}$, but for directions mostly perpendicular to the magnetic Lshells. For this reason, contrary to the KSR case (Koustov et al., 2006), the HOK velocity cannot be as large as fast SAPS flows observed mostly along the L-shell direction (Ridley and Liemohn, 2002; Baker et al., 2007). Clearly, the high number HOK beams would be preferable for SAPS studies. However, the first year of the radar operation showed occasional excessive noise levels in the beams 9-12 so that echo occurrence is not high there. Observations in the highnumber beams do show reasonable rates of echo occurrence (Hosokawa et al., 2007), but the velocities are not very large in magnitude probably because measurements are carried out at relatively low magnetic latitudes of $\Lambda<50^{\circ}$ where the flows are usually decreased. Exceptional events with SAPS at low latitudes similar to the ones reported by Yeh et al. (1991) are expected but strong magnetic activity, needed for such events, has not been observed over the entire year 2007.

To demonstrate the overall Hokkaido radar performance, we made statistics for the echo occurrence and median velocity for beams 4-6, see dark shading in the Hokkaido radar field of view in Fig. 1. Data for only one month of continuous radar operation, April 2007, are presented here; the reason for this selection was that the major event to be considered occurred on 1 April 2007. Similar statistical analysis has been performed for March 2007, and the data showed very similar results.

Echoes in two magnetic latitude bands were considered separately, the high-latitude band between $60^{\circ}$ and $65^{\circ}$ and the low-latitude band between $55^{\circ}$ and $60^{\circ}$. This is to see the magnetic latitude effect. Also, because the overall HOK echo occurrence is not high, one hour bins of the magnetic local time were implemented. The computations of the echo occurrence rate and median velocity were done similar to Koustov et al. (2004).

Figures $2 \mathrm{a}$ and $\mathrm{b}$ are line plots of the echo occurrence and median velocity versus magnetic local time for the above two 
bands of magnetic latitude. Most of the time, the occurrence rate is very low except for the pre-midnight sector between 18:00 and 22:00 MLT for which the rates are as high as 4\%, Fig. 2a. This number is somewhat low compared to the KSR observations (Koustov et al., 2006) but one has to keep in mind that the HOK observations were carried out during the solar cycle minimum when the number of echoes is dramatically reduced (Ruohoniemi and Greenwald, 1997; Koustov et al., 2004). Echo occurrence rate is higher at $\Lambda>60^{\circ}$ consistent with a more frequent irregularity excitation at higher magnetic latitudes (Fejer and Kelley, 1980). In terms of typical velocities, Fig. 2b, the largest are observed between 18:00 and 22:00 MLT at magnetic latitudes of $\Lambda>60^{\circ}$. The velocity magnitudes are below $150 \mathrm{~m} / \mathrm{s}$ in remarkable contrast to high velocities $(>500 \mathrm{~m} / \mathrm{s}$ ) usually detected by the KSR radar (Koustov et al., 2006). One might argue that, contrary to the KSR radar case, the HOK radar observes at large flow angles, and this is the reason for the difference in the typical velocities. If the flow is predominantly along the magnetic L-shells, then the velocity of $\sim 150 \mathrm{~m} / \mathrm{s}$ would corresponds roughly to $\sim 250 \mathrm{~m} / \mathrm{s}$, which is still well below of what the KS radar usually sees.

We note at this point that, while the KSR radar typically detects echoes through the direct propagation mode, the HOK radar receives the echoes considered here at the far edge of its FoV through $1 \& 1 / 2$ hop propagation mode. The HOK observations are thus more delicate as proper propagation conditions are required all along the very long radar wave path.

\section{The event of 1 April 2007}

The statistical analysis performed indicates that detection of fast flows with the Hokkaido radar is not a frequent phenomenon. Such flows, however, are of a primary interest as they would reflect stronger driven SAPS conditions that are easier to study with other instrumentation and probably easier to investigate the ongoing physics. Manual search through the data quick look plots identified very few events (handful for the entire year 2007) with velocities of more than $500 \mathrm{~m} / \mathrm{s}$. One of these unusual events occurred on 1 April 2007.

\subsection{Hokkaido radar data}

Figure $3 \mathrm{a}, \mathrm{b}$ shows the velocity of the Hokkaido echoes for the event of 1 April 2007. In Fig. 3a, the 1-o-s velocity in beam 6 is plotted in $\Lambda$-UT coordinates between 05:00 and 11:00 UT. One can notice two "blue blobs" of echoes with velocity exceeding $600 \mathrm{~m} / \mathrm{s}$ at $\Lambda \sim 64^{\circ}$ between $06: 00$ and 07:00 UT and at $\Lambda \sim 62^{\circ}$ between 08:00 and 09:00 UT. These are exceptionally high velocities as compared to the typical Hokkaido values of $<150 \mathrm{~m} / \mathrm{s}$. Both events lasted for about $30-40 \mathrm{~min}$. For the first blob, the echoes were of high ve-

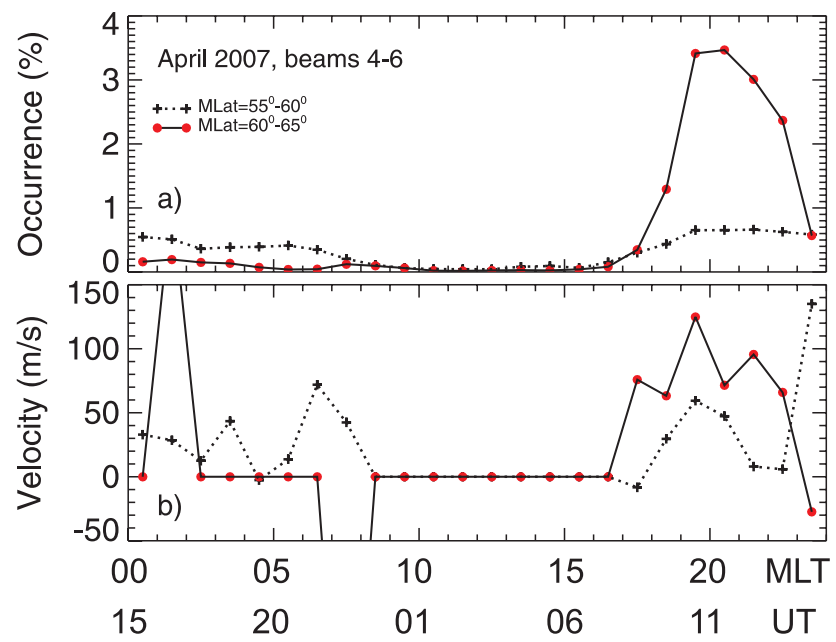

Fig. 2. (a) Hokkaido echo occurrence rate and (b) median velocity versus magnetic local time in two bands of latitudes for observations in April 2007. Only data in beams 4-6 are considered. The Universal Time scale corresponds to the radar location.

locity right from the start. It seems that if the radar had a chance to monitor echoes at higher latitudes, they would have been seen there as well. For the second blob, the highvelocity echoes were seen at the far edge of the echo band; the radar had chances to see echoes at farther ranges, but did not detect them. For both blobs, the velocity gradually decreased toward lower latitudes. Overall, the HOK ionospheric echo band was shifting equatorward between $\sim 08: 00$ and 10:00 UT. The ground scatter echoes were steadily increasing their latitudes between 06:00 and 08:00 UT perhaps reflecting the overall decrease of the F-region electron density as the sun was setting below the horizon.

Figure $3 b$ presents the standard velocity map (in geomagnetic coordinates) for the moment indicated in Fig. 3a by a vertical dashed line. This line corresponds to the time of fast flow detection. One can see that the high velocity echoes occurred in beams $6-8$, and the echoes were not seen as much in larger number beams, except for at much lower magnetic latitudes. We comment that the velocity was decreasing with latitude, starting from the blue blob. We also note that if one assumes the flow is L-shell aligned, then by dividing by the cosine of the L-shell angle, one gets the total velocity in excess of $1.5 \mathrm{~km} / \mathrm{s}$.

\subsection{King Salmon radar data}

Figure $3 c$, $d$ shows that KSR radar velocity data in the same format as the HOK data in Fig. 3a, b (notice a change in the velocity scale). One can certainly realize that although the KSR velocity magnitudes are comparable to the ones at HOK, the echoes occur at different times and in different latitudinal locations. In some way, the data complement each other, although one needs to keep in mind the following 

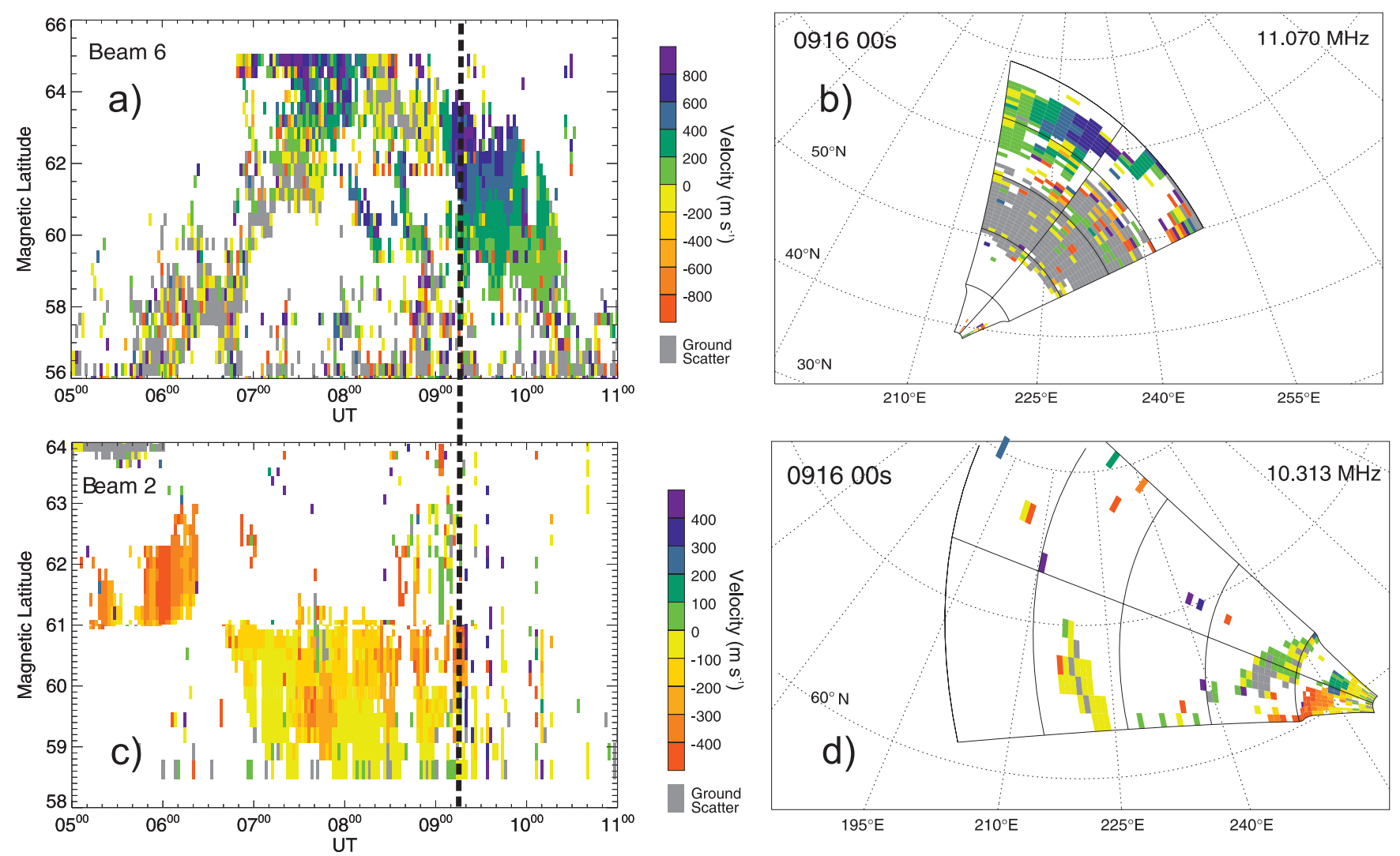

Fig. 3. (a) Echo velocity in beam 6 of the Hokkaido radar for 1 April 2007 between 05:00 and 11:00 UT. (b) Velocity map for the period of the fast flow detection (dashed line in panel a). (c) and (d) are the corresponding KSR radar data in the same format.

circumstance. Examination of the velocity map, Fig. 3d, indicates that the echoes at the lowest KSR latitudes were probably received from the E-region, and their velocity can be well below the $\boldsymbol{E} \times \boldsymbol{B}$ drift (Koustov et al., 2005). This would explain why the HOK echoes, occasionally detected at the same latitudes (e.g. at $\Lambda \sim 60.5^{\circ}$, vertical line) as the KSR echoes, have comparable velocity magnitudes even though the L-shell angles are better for the KSR radar. We notice that the largest KSR velocities of $\sim 500 \mathrm{~m} / \mathrm{s}$ were observed at the beginning of the period under investigation.

If one compares the KSR and HOK data, one can see that the HOK high-velocity blobs (blue color) were observed for longer period of time than the KSR high-velocity echoes (red color). For the second period, the KSR echoes disappeared after $\sim 09: 20$ UT. On the other hand, the KSR radar highvelocity blob around 08:00 UT does not have a counterpart in the Hokkaido data.

\subsection{Comparison with DMSP measurements}

Over the event duration, DMSP F13, F15 and F16 satellites crossed the area of observations so that inter-comparison of measurements is possible.
Figure 4a-f shows the Hokkaido (left column) and King Salmon (right column) velocity maps corresponding to the periods when the satellites were in close vicinity to the highvelocity echo blobs. The cross-track component of the $\boldsymbol{E} \times \boldsymbol{B}$ ion drift measured at $\sim 830 \mathrm{~km}$ by the satellites is presented by lines starting from the dots (the satellites' track locations). Satellite particle data indicate that the equatorial edge of the auroral oval was located at a magnetic latitude of $\sim 64^{\circ}$; a black marker indicates this latitude in Fig. 4a, c, e.

For the frames at 07:14 UT, the high-velocity HOK echoes were mostly received from the area near the equatorial edge of the oval. This result is similar to the ones of Koustov et al. (2006). The KSR echoes were located clearly equatorward of the oval. The DPSP F13 sees a double-hump flow structure with one hump corresponding to the oval flow and the other one to the flow equatorward of the oval. The latter can certainly be classified as SAPS. Closer examination of the HOK frame, Fig. 4a, shows some SAPS signatures (a narrow band of echoes in beams 0-5) although this cannot be ascertained without knowing that the SAPS should exist there (as inferred from the F13 data).

For the frame at 08:28 UT, the radar data are very similar to those at $07: 14 \mathrm{UT}$, for both radars. It is worthy to note that DMSP F15 shows a strong SAPS flow at about the same 


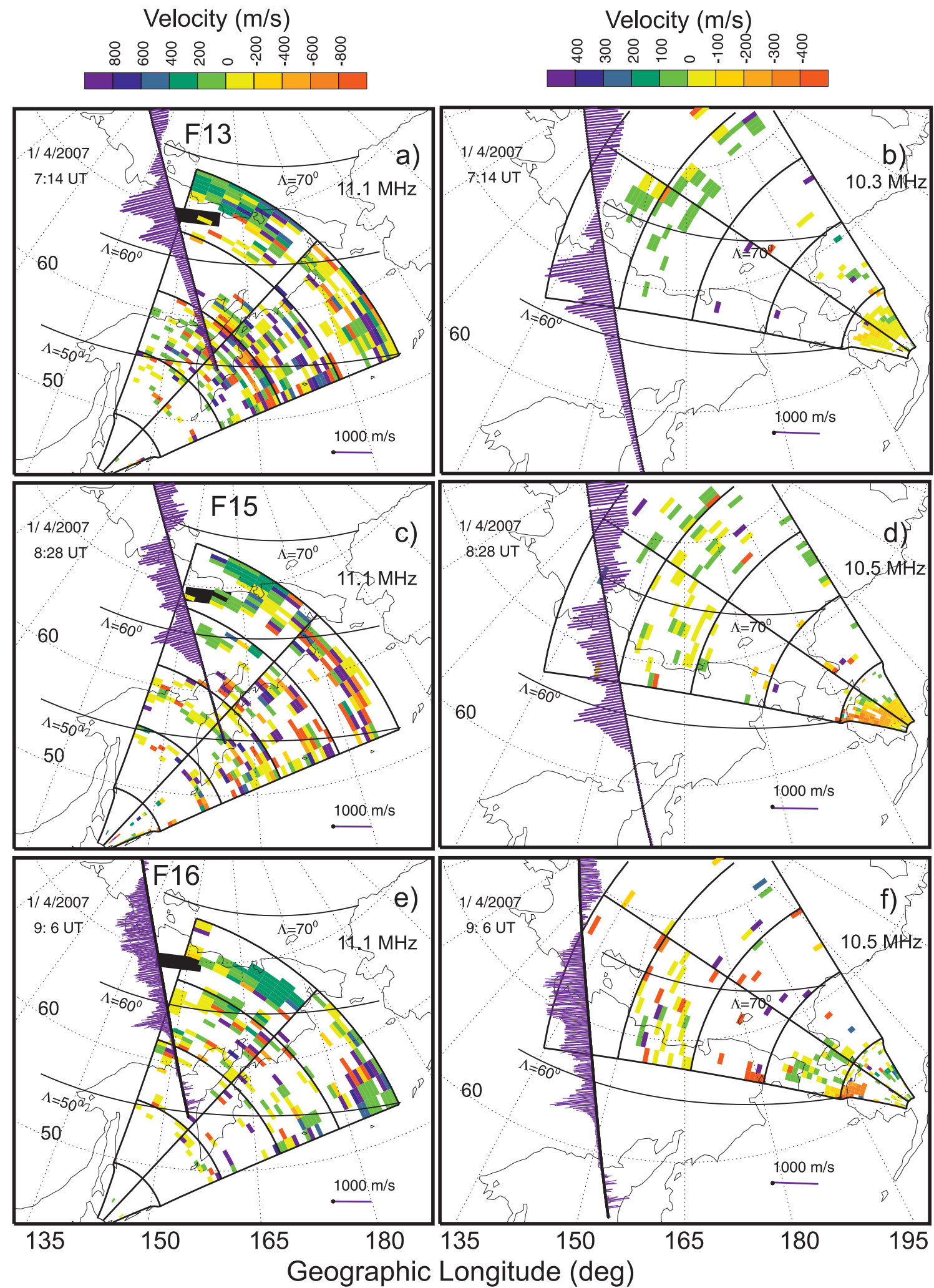

Fig. 4. SuperDARN velocity maps for the Hokkaido (left column) and King Salmon (right column) radars on 1 April 2007 and cross-track ion drift measured concurrently by the DMSP satellites. The black marker indicates an approximate position of the equatorial edge of the auroral oval. 
1 April 2007:

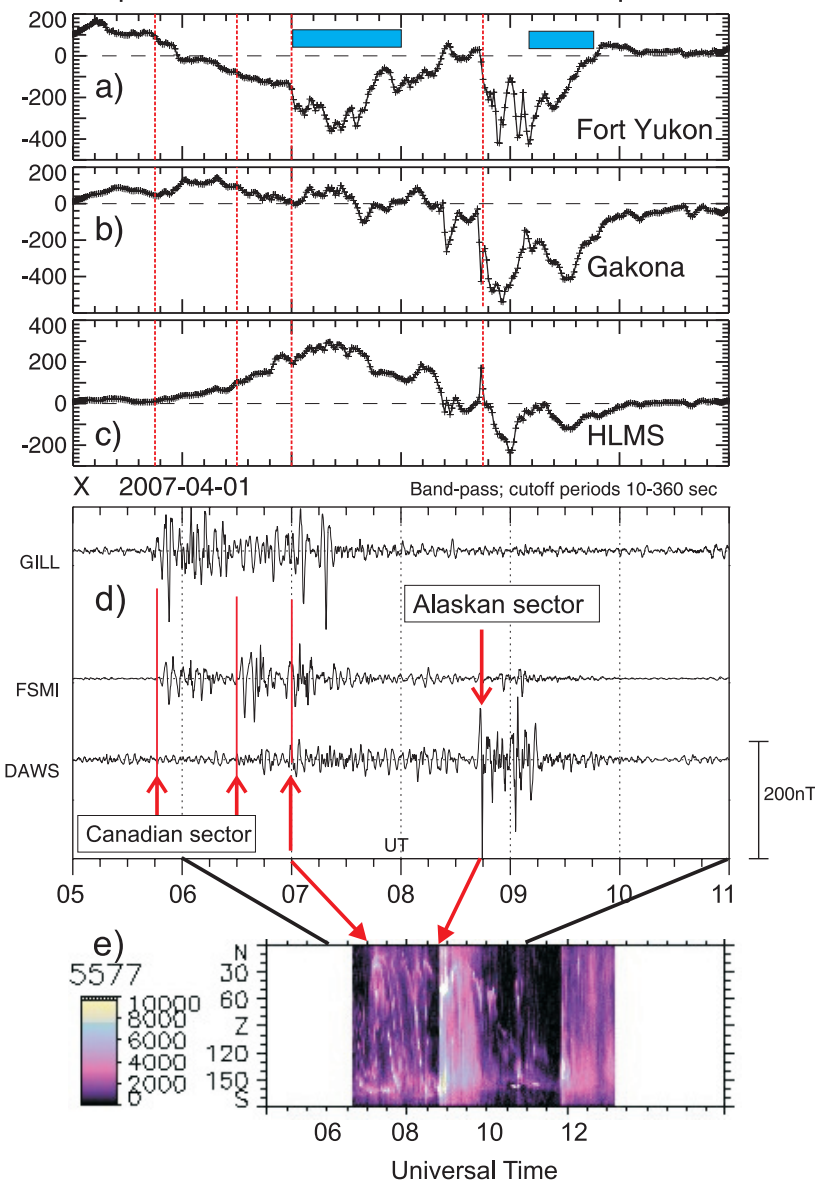

Fig. 5. (a-c) Magnetic H-components according to measurements at Fort Yukon, Gakona and High Latitude Monitoring Station on 1 April 2007. Horizontal blue bars on panel (a) denote the periods of high-velocity echo detection with the HOK radar. (d) Pi2 magnetic pulsations in the X-component of the Earth's magnetic field at Canadian stations Gillam, Fort Smith and Dawson. (e) Poker Flat (Alaska) photometer records of the auroral luminosity in $557.7 \mathrm{~nm}$ line. The moments of the substorm onsets are indicated by vertical lines and arrows.

latitudes as F13 but more than one hour later. The SAPS feature is seen on the 08:28 UT frame at $\Lambda \sim 60^{\circ}$, and also in the data of Fig. 3a where enhanced velocities at $\Lambda \sim 60^{\circ}-61^{\circ}$ are well seen as a cluster of blue-color dots.

For the frame at 09:06 UT, after $\sim 30$ min have passed, the SAPS flow is still present, according to the DMSP F16 and KSR observations. The HOK data show some signatures of SAPS but at slightly larger latitudes of $59^{\circ}-61^{\circ}$; this mismatch in latitude could be the result of improper echolocation mapping. There are other echoes equatorward of $\sim 64^{\circ}$, their velocity is above typical velocities but is not as strong as it becomes in about 10 min (Fig. 3a, b shows strong flows that can be classified as SAPS starting from $\sim 09: 10$ UT).
One clear conclusion from the above DMSP-radar comparison is that for the event under consideration, the SAPS flows existed for a long period of $\sim 2.5 \mathrm{~h}$ and the HOK and KSR radars, complementing each other, provided 2-D information on these flows most of the time.

3.4 Geophysical conditions and high-velocity echo occurrence

First of all, we note that the event occurred during a minor magnetic storm; the $D_{s t}$ index was at its minimum for the day at around $-60 \mathrm{nT}$. The Sym-H index was fairly stable for several hours around the interval of interest. The $K_{p}$ index was $4+$.

Figure 5a-c summarizes geophysical conditions according to observations in the Alaskan sector of the Arctic. Figure 4a shows magnetic field $\mathrm{X}$-component variations at Fort Yukon, Gakona and High Latitude Monitoring Station (HLMS). Table 1 gives information on these magnetometers. Horizontal light-blue bars in Fig. 4a indicate periods of high-velocity echo detection with the HOK radar. One can see that the first period of high-velocity echo detection corresponds to negative (positive) magnetic perturbation at FYU (HMLS) while the second period corresponds to the negative perturbations at all sites.

Figure $5 \mathrm{~b}$ presents $\mathrm{Pi} 2$ magnetic pulsations data at Gillam, Fort Smith and Dawson. Onsets at $\sim 05: 45,06: 30,07: 00$ and 08:45 UT are identifiable. These are periods for substorm development with the last one located in the Alaskan sector. Substorm development at all the above moments is supported by the photometer records at Gillam and Poker flat; data for the latter are presented in Fig. 5c. The moments of the substorm onset are indicated by vertical lines in Fig. $5 \mathrm{a}-\mathrm{c}$. The onset of the last substorm is well seen as a sharp increase in the flux of energetic particles on the LANL satellite 1989046 and as a sharp decrease of the AL magnetic index.

An important conclusion from the data survey is that the first period of the fast HOK echoes occurred during moderately disturbed condition right after the substorm onset in the nearby area while the second period of the fast HOK echoes occurred about 25 min after the substorm onset over Alaska.

\section{Comprehensive Ring Current model predictions for the high-velocity radar echo onset}

The Comprehensive Ring Current model (Fok et al., 2001; Ebihara et al., 2004) has been widely used for investigations of various subauroral phenomena. With respect to the Hokkaido observations, the model was successful in identifying the convection reversal latitudes in the midnight sector (Kataoka et al., 2007) and over-shielding events (Ebihara et al., 2008). In this study we attempt to assess whether it can predict the onset of high-velocity echoes identified by the HOK and KSR radars. To accomplish this, simulations 
Table 1. Magnetometer notation and location.

\begin{tabular}{lccccc}
\hline Magnetometer & Abbreviation & $\begin{array}{c}\text { Geog. } \\
\text { Lat (deg) }\end{array}$ & $\begin{array}{c}\text { Geog. } \\
\text { Lon (deg) }\end{array}$ & $\begin{array}{c}\text { CGM } \\
\text { Lat (deg) }\end{array}$ & $\begin{array}{c}\text { CGM } \\
\text { Lon (deg) }\end{array}$ \\
\hline Gillam & GILL & 56.4 & 265.4 & 66.7 & -28.2 \\
Fort Smith & FSMI & 60.0 & 248.05 & 67.7 & 54.9 \\
Dawson & DAW & 64.1 & 220.9 & 66.0 & 87.8 \\
Fort Yukon & FYU & 66.6 & 214.8 & 67.3 & 261.3 \\
Gakona & GAK & 62.4 & 214.8 & 63.5 & 265.7 \\
High Lat. Monitor. Station & HLMS & 61.2 & 210.1 & 62.4 & 251.1 \\
\hline
\end{tabular}

were performed for the 1 April 2007 event by applying the standard procedure as outlined in Ebihara et al. (2008). Hot ions are considered to be injected into the inner magnetosphere from the nightside boundary, constituting the major part of the ring current. The distribution function of the hot ions at the outer boundary was determined using data from 4 LANL geosynchronous satellites (Bame et al., 1993). Thus, it was attempted to take changes in the plasma sheet ions into account. The electric field potential distribution in the inner magnetosphere was calculated by solving the Poisson equation to maintain continuity of the electric current flowing between the ring current and the ionosphere. The electric potential at the poleward boundary at $\Lambda=64^{\circ}$ was imposed by the Weimer-2000 type convection electric field model (Weimer, 2001) that depends on the solar wind and interplanetary magnetic field. Empirical conductivity models associated with solar EUV radiation and auroral electron precipitations were employed.

Figure 6 compares the model predictions with the Hokkaido measurements. To accomplish this, the computed vector of plasma flow for each location along the radar beam 6 was projected onto the corresponding direction of the beam thus producing the expected line-of-sight velocity. The model, Fig. 6b, shows three periods of enhanced velocity (blue blobs): 06:30-07:30 UT, 08:30-09:00 UT and 09:1009:45 UT. The first and the last periods coincide well with the times of the fast HOK flows and the timing is of exceptional quality for the last period. For this period, the model shows a gradual velocity decrease with latitude, and the predicted typical latitudes for fast flows coincide with those observed. We have to mention, however, that the velocity magnitudes are different by a factor of 2 . For the first period, the model gives lower latitudes of the high-velocity echoes; for some of these locations HOK echoes were not detected at all while for others they were even of opposite polarity. The HOK echoes were of different polarity for the period 08:30-09:00 UT as well.

Figure 7 compares the model predictions with the King Salmon radar measurements. The model, Fig. 7b, shows enhanced velocity (red color) between 05:00 and 10:00 UT with particularly fast velocities of $\sim-750 \mathrm{~m} / \mathrm{s}$ between $05: 30$ and

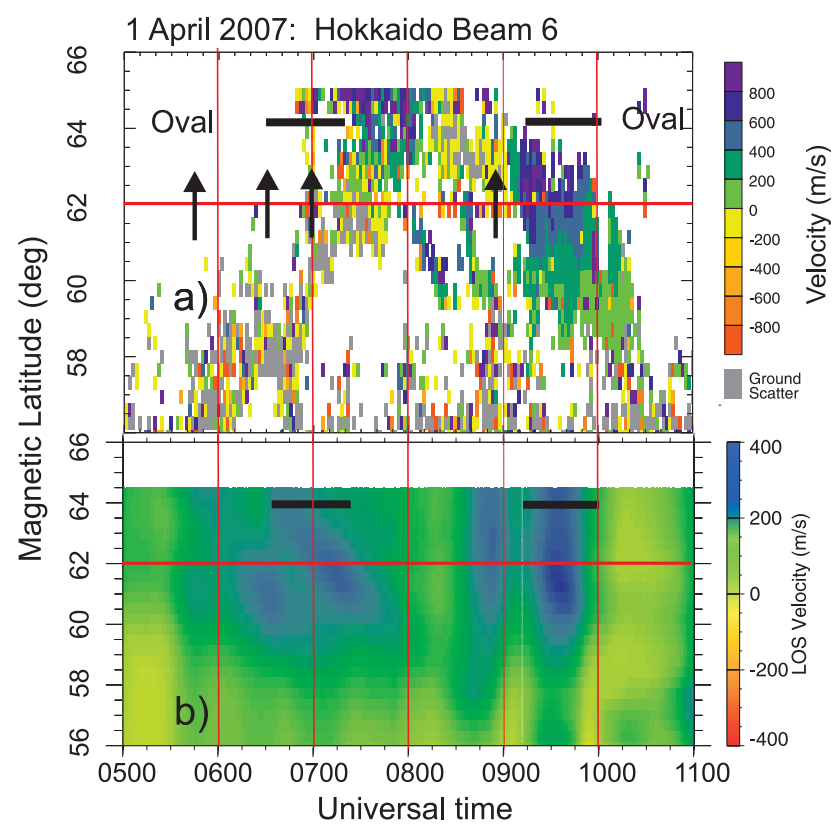

Fig. 6. (a) The Hokkaido radar velocity in beam 6 versus time for the 1 April 2007 event (the same plot as in Fig. 3a) and (b) predicted velocity according to the Comprehensive Ring Current model. Notice the difference in the velocity scale for observations and modeling. Horizontal line $\Lambda=62^{\circ}$ is given to facilitate the intercomparison. Also marked are the estimated latitude of the Feldstein-Starkov auroral oval (Feldstein and Starkov, 1967) and the moments for the substorm onsets.

07:30 UT. For this period, the KSR echoes were observed for a shorter interval, 05:45-06:20 UT. The KSR velocities, $\sim-500 \mathrm{~m} / \mathrm{s}$, were very comparable with the predicted ones. From 07:00 to 09:00 UT, there is no obvious agreement between the model and measurements. The observed velocities are sometimes significantly smaller or larger in magnitude than the predicted ones. In addition, the model shows smooth variations while the KSR data show distinct/discrete blobs of enhanced velocity. 


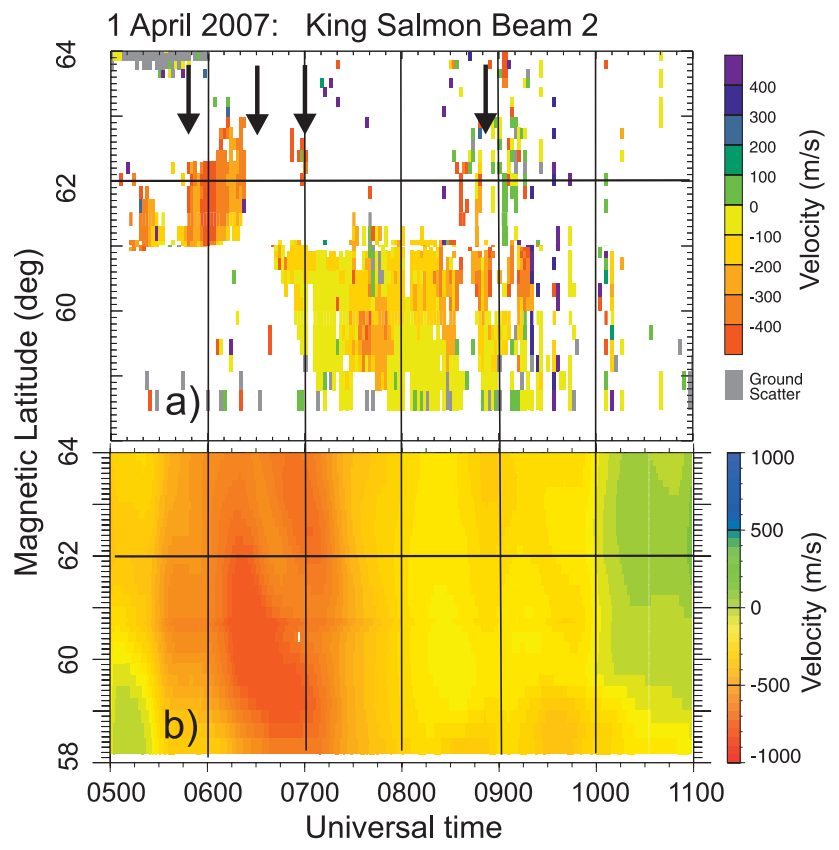

Fig. 7. The same as in Fig. 6 but for the King Salmon radar, beam 2 . Auroral oval was located at $\Lambda \sim 64^{\circ}$, at the top of the panels.

\section{Discussion and summary}

In this study we presented a case of exceptionally highvelocity echo detection with the relatively new Hokkaido SuperDARN radar. The velocities were about 5 times larger than is typically observed. Visually, two separate velocity intensifications were identified. For the first one, the echoes were seen at relatively high magnetic latitudes of $\Lambda \sim 64^{\circ}-65^{\circ}$ while for the second one they were at latitudes of $\Lambda \sim 62^{\circ}$. The concurrently operated King Salmon radar also detected relatively high-velocity echoes for both HOK intensifications although they were seen for a shorter period of time. In addition, they were at somewhat lower latitudes and of a smaller magnitude for the second HOK event. The unexpectedly low magnitudes of the KSR echoes during the second period can be explained by the E-region scatter contamination (that generally gives velocities smaller than the $\boldsymbol{E} \times \boldsymbol{B}$ drift, Koustov et al., 2005) because the echoes were received from short ranges of $<650 \mathrm{~km}$.

Comparison of the radar observations with the concurrent measurements of the $\boldsymbol{E} \times \boldsymbol{B}$ drift on the DMSP satellites showed that the first HOK velocity intensification was observed from within the auroral oval while the second one was located equatorward of the auroral oval edge and it can be classified as the true SAPS flow. The satellites indicated somewhat stronger equatorward extension of SAPS, up to magnetic latitudes of $\sim 57^{\circ}$ (Figs. 3a and 4d, e, F16 data). Although the Hokkaido radar was capable of detecting echoes at these latitudes, only patchy ones with moderate velocities (still above the typical ones) were seen at these latitudes.
Absence of echoes might be caused by the unfavorable conditions for the irregularity production at these latitudes. The other reason could be poor propagation conditions. Indeed, the velocity maps, e.g. Fig. 3b, show that ground scatter was in effect for shorter ranges preventing radar waves at certain elevation angles from penetrating farther/deeper into the $\mathrm{F}$ layer and thus from arrival to the required latitudes. We speculate that another possible effect is generally low electron densities in the areas of strong SAPS flows (e.g. Foster and Burke, 2002). In this case, the coherent echo power cannot be strong, as it is documented for the E-region echoes (e.g. Starkov et al., 1983). We conclude that, although generally speaking, the HOK radar probably detects the SAPS flows quite often, the identification of fast events from the radar data alone is not straightforward. This conclusion is only applicable to the considered period of solar cycle minimum. It should be noted that the 1 April 2007 event was one of a few really fast events identified for the first year of radar operation.

The DMSP data showed persistence of SAPS for at least $2 \mathrm{~h}$, and one can talk about the "dormant" and stable SAPS (Makarevich and Dyson, 2007). Moreover, during these $2 \mathrm{~h}$, several substorms occurred to the East of the radars FoV, and one might think that the substorms did not affect the SAPS occurrence/characteristics. We disagree with this notion. We would like to point out on changes in the latitude of the SAPS velocity maxima and the latitudinal distribution of the velocity. The next argument would be that the radar data show significant variability of the velocity at SAPS latitudes, for example the KSR data between 08:30 and 09:30 UT. This is consistent with previous reports (e.g. Oksavik et al., 2006), but in our case we would like to relate the high-velocity blobs with substorm occurrence. For the major HOK event, the maximum velocities were achieved about 25 min after the substorm onset (at 09:45 UT). The largest KSR velocity magnitudes were also achieved about 25 min after the substorm onset although the velocity started to grow prior to the onset (Fig. 7a). The KSR radar observed the fastest velocities about $15 \mathrm{~min}$ after the substorm at 05:45 UT and there was a $\sim 30$ min delay for the high-velocity echo onset after the substorm at 07:00 UT. These delays are very consistent with other reports (Anderson et al., 1993; Koustov et al., 2006; Makarevich and Dyson, 2007). Our additional argument comes from the comparison of the CRC model predictions and radar observations. We showed that even when the model was consistent time-wise and in terms of the magnetic latitudes with the radar measurements, the velocity magnitudes were significantly under-predicted. This is exactly that one would expect if the substorms do contribute to the intensity of SAPS. In the CRC modeling, the ion fluxes from the tail were taken into account, but it is hardly possible to do it properly for substorm periods with only few satellites available (in reality, only the one in the dusk sector would give vital information). Additional ion injections during the substorm expansive phase would bring more of them to the dusk 
sector and thus would provide stronger charge separation as the model by Galperin (2002) anticipates.

We would like to discuss one point of the modelobservations disagreement. The model predicted strong SAPS flows between 08:30 and 09:00 UT for the HOK radar, Fig. $6 \mathrm{~b}$ and minor intensification for the KSR radar, Fig. 7b. This is exactly the period of the substorm growth phase with the eventual onset over Alaska. The KSR radar showed some velocity intensification but it actually started $20-30$ min earlier. The HOK radar showed the velocity polarity opposite to predictions. These disagreements are not a surprise because the CRC model does not fully take into account the substorm processes. The KSR data for 08:30-09:00 UT are consistent with the flow intensification and formation of stronger shears prior to a substorm, as reported in the past (e.g. Bristow and Jensen, 2007). The HOK data during this period also indicate formation of strong sheared flow at the equatorial edge of the oval (Bristow and Jensen, 2007). It is interesting that during this short period, the HOK echoes were received from the equatorial edge of the auroral oval while the KSR echoes were received at latitudes equatorward of the oval. This is despite the fact that the HOK radar is located at mid-latitudes while the KSR radar is located in the auroral zone. This feature tells us that the low-latitude location of the HOK radar does not automatically mean that SAPS detection is superior with this radar. It seems that a combination with the KSR radar works better. Perhaps, as we have already mentioned, the need for $1 \& 1 / 2$ hop radar wave propagation for SAPS detection with the HOK radar somewhat diminishes its potential.

The results of this study can be summarized as follows:

1. The Hokkaido SuperDARN radar, whose FoV for low number beams extends between magnetic latitudes of $40^{\circ}$ and $65^{\circ}$, shows an enhanced echo occurrence rate of up to $\sim 4 \%$ in the dusk sector, between 18:00 and 24:00 MLT and at magnetic latitudes of $60^{\circ}-65^{\circ}$. A typical velocity of these echoes is $100-150 \mathrm{~m} / \mathrm{s}$. At lower latitudes of $55^{\circ}-60^{\circ}$, the echo occurrence rate drops down significantly, to $\sim 0.5 \%$, and the typical velocities are smaller, $\sim 50 \mathrm{~m} / \mathrm{s}$. These conclusions are based on two months of observations in March-April 2007.

2. Occasionally, echoes with velocity of more than $600 \mathrm{~m} / \mathrm{s}$ are observed. Some of these echoes occur at latitudes within the auroral oval. In this case, the enhanced velocity of the echoes is very likely related to the substorm processes. For the 1 April 2007 event, investigated in detail, the high-velocity echoes were seen from the very beginning of the substorm onset developed in the area to the East of the Hokkaido FoV. The concurrently operated King Salmon SuperDARN radar also detected enhanced flows, in agreement with the Hokkaido observations, although at lower latitudes, equatorward of the auroral oval. Thus the King Salmon radar was monitoring the SAPS flows. The velocity of the King Salmon echoes was clearly enhanced about $30 \mathrm{~min}$ after the substorm onset in agreement with Koustov et al. (2006). The King Salmon velocity magnitudes were not particularly high because the echoes were either received from the E-region or were contaminated by the E-region scatter.

3. Some of the high-velocity Hokkaido echoes occur equatorward of the auroral oval so that the radar provides information on SAPS flows. In these instances, the Hokkaido and King Salmon radars act as the complementary instruments. For the 1 April 2007 event, the SAPS velocities of $>600 \mathrm{~m} / \mathrm{s}$ were only clearly identifiable in the Hokkaido data $\sim 25 \mathrm{~min}$ after the substorm onset despite the fact that the DMSP satellites reported enhanced SAPS flows both prior to and after the onset, although at somewhat lower latitudes. The high-velocity Hokkaido echoes were mostly seen close to the equatorial edge of the auroral oval. The radar did show signatures of relatively low-latitude flows that were certainly SAPS, but their identification from the radar data alone was not obvious. The Hokkaido flows of $>600 \mathrm{~m} / \mathrm{s}$ lasted for $\sim 45 \mathrm{~min}$. For this specific flow intensification, both the period and the latitudinal extent were in good agreement with the predictions of the Comprehensive Ring Current model described by Fok et al. (2001) and Ebihara et al. (2004). The measured velocity magnitudes were about 2 times larger than the predicted ones; this disagreement was attributed to the fact that the model does not fully take into consideration the substorm processes, first of all injection of additional ions fluxes towards the Earth that may enhance the charge separation (polarization electric fields) on the duskside of the inner magnetosphere.

4. For the 1 April 2007, the Comprehensive Ring Current model predicted fast SAPS flows for several other periods. For at least one of them, the Hokkaido data did not confirm the SAPS onset while the KSR data did not contradict to the prediction. For this period, the substorm growth phase was in progress (with the eventual substorm occurrence in a nearby area) and corresponding changes in the convection pattern, reported in other SuperDARN publications, were seen. This model-radar inconsistency, once again, supports the notion that the substorm-related processes affect the SAPS flows and chances to detect them with HF radars.

5. The Hokkaido data for the 1 April 2007 event and for several other events, investigated so far, indicate that the highest-velocity Hokkaido echoes within the SAPS channel occur with a delay after the substorm onset. The velocity magnitude can start to increase near or even prior to the substorm onset, but the maximum velocity is achieved with a delay of the order of $30 \mathrm{~min}$, in agreement with the report by Koustov et al. (2006) for 
the King Salmon radar. Thus both SuperDARN radars point at an important role of the substorm processes in achieving maximum polarization electric fields at latitudes equatorward of the auroral oval, in agreement with the conceptual model of Galperin (2002).

Acknowledgements. The use of the data provided by following projects/individuals are acknowledged: magnetometer and photometer observations, CARISMA (I. Mann) and NORSTAR (E. Donovan) projects of the Canadian Geospace Monitoring Program (Canadian Space Agency), Alaskan magnetometer and photometer observations run by the Geophysical Institute, University of Alaska, Fairbanks (GIMA project), DMSP particle data (APL, Johns Hopkins University, P. Newell), GUVI satellite aurora imaging (APL, Johns Hopkins University), and LANL satellite particle measurements (CDAWeb site, E. Dors). Information on $K_{p}$ and $\mathrm{AL}$ indices were obtained from the WDC for Geomagnetism, Kyoto. We thank F. Rich (Air Force Research Laboratory) for providing access to the DMSP data on the AFRL website; this enormously helped us in data search. The authors gratefully acknowledges M. F. Thomsen for providing data from the MPA instrument on the LANL satellites. This work was supported by the Grant-in Aid for Scientific Research 19403010 from the Ministry of Education, Culture, Sports, Science and Technology of Japan. Part of this study was supported by the Program for Improvement of Research Environment for Young Researchers from the Special Coordination Funds for Promoting Science and Technology (SCF) commissioned by the Ministry of Education, Culture, Sports, Science and Technology (MEXT) of Japan. AVK acknowledges the Solar-Terrestrial Environment Laboratory of Nagoya University for funding during his stay in Japan. This work has been also supported by NSERC (Canada) grant to AVK.

Topical Editor M. Pinnock thanks two anonymous referees for their help in evaluating this paper.

\section{References}

Anderson, P. C., Heelis, R. A., and Hanson, W. B.: The ionospheric signatures of rapid subauroral ion drifts, J. Geophys. Res., 96, 5785-5792, 1991.

Anderson, P. C., Hanson W. B., Heelis, R. A., Craven, J. D., Baker, B. N., and Frank, L. A.: A proposed production model of rapid subauroral ion drifts and their relationship to substorm evolution, J. Geophys. Res., 98, 6069-6078, 1993.

Anderson, P. C., Carpenter, D. L., Tsuruda, K., Mukai, T., and Rich, F. J.: Multisatellite observations of rapid subauroral ion drifts (SAID), J. Geophys. Res., 106, 29 585-29 599, 2001.

Baker, J. B. H., Greenwald, R. A., Ruohoniemi, J. M., Oksavik, K., Gjerloev, J. W., Paxton, L. J., and Hairston, M. R.: Observations of ionospheric convection from the Wallops SuperDARN radar at middle latitudes, J. Geophys. Res., 112, A01303, doi:10.1029/2006JA011982, 2007.

Bame, S. J., McComas, D. J., Thomsen, M. F., Barraclough, B. L., Elphic, R. C., Glore, J. P., Gosling, J. T., Chavez, J. C., Evans, E. P., and Wymer, F. J.: Magnetospheric plasma analyzer for spacecraft with constrained resources, Rev. Sci. Instr., 64, 1026-1033, 1993.
Bristow, W. A. and Jensen, P.: A superposed epoch study of SuperDARN convection observations during substorms, J. Geophys. Res., 112, A06232, doi:10.1029/2006JA012049, 2007.

Galperin, Y. I.: Polarization jet: Characteristics and a model, Ann. Geophys., 20, 391-404, 2002, http://www.ann-geophys.net/20/391/2002/.

Ebihara, Y., Fok, M.-C., Wolf, R. A., Immel, T. J., and Moore, T. E.: Influence of ionosphere conductivity on the ring current, J. Geophys. Res., 109, A08205, doi:10.1029/2003JA010351, 2004.

Ebihara, Y., Nishitani, N., Kikuchi, T., Ogawa, T., Hosokawa, K., and Fok, M.-C.: Two-dimensional observations of overshielding during a magnetic storm by the Super Dual Auroral Radar Network (SuperDARN) Hokkaido radar, J. Geophys. Res., 113, A01213, doi:10.1029/2007JA012641, 2008.

Fejer, B. G. and Kelley, M. C.: Ionospheric irregularities, Rev. Geophys. Space Phys., 18, 401-454, 1980.

Feldstein, Y. I. and Starkov, G. V.: Dynamics of auroral belt and polar geomagnetic disturbances, Planet. Space Sci., 18, 401-454, 1967.

Fok, M.-C., Wolf, R. A., Spiro, R. W., and Moore, T. E.: Comprehensive computational model of Earth's ring current, J. Geophys. Res., 106, 8417-8424, 2001.

Foster, J. C. and Vo, H. B.: Average characteristics and activity dependence of the subauroral polarization stream, J. Geophys. Res., 107, 1475, doi:10.1029/2002JA009409, 2002.

Foster, J. C., Erickson, P. J., Lind, F. D., and Rideout, W.: Millstone Hill coherent-scatter radar observations of electric field variability in the sub-auroral polarization stream, Geophys. Res. Lett., 31, L21803, doi:10.1029/2004GL021271, 2005.

Greenwald, R. A., Baker, K. B., Dudeney, J. R., Pinnock, M., Jones, T. B., Thomas, E. C., Villain, J.-P., Cerisier, J.-C., Senior, C., Hanuise, C., Hunsuker, R. D., Sofko, G., Koehler, J., Nielsen, E., Pellinen, R., Walker, A. D. M., Sato, N., and Yamagishi, H.: DARN/SuperDARN: A global view of the dynamics of highlatitude convection, Space Sci. Rev., 71, 763-796, 1995.

Hosokawa, K., Nishitani, N., Kataoka, R., and Ogawa, T.: Initial backscatter occurrence statistics from the Hokkaido SuperDARN radar, Paper presented at the Annual SuperDARN Workshop, 48 June, Abashiri, Hokkaido, Japan, 2007.

Kataoka, R., Nishitani, N., Ebihara, Y., Hosokawa, K., Ogawa, T., Kikuchi, T., and Miyoshi, Y.: Dynamic variations of a convection flow reversal in the subauroral postmidnight sector as seen by the SuperDARN Hokkaido HF radar, Geophys. Res. Lett., 34, L21105, doi:10.1029/2007GL031552, 2007.

Koustov, A. V., Sofko, G. J., Andre, D., Danskin, D. W., and Benkevitch, L. V.: Seasonal variation of HF radar F region echo occurrence in the midnight sector, J. Geophys. Res., 109, A06305, doi:10.1029/2003JA010337, 2004.

Koustov, A. V., Danskin, D. W., Makarevitch, R. A., and Gorin, J. D.: On the relationship between the velocity of E-region HF echoes and $\boldsymbol{E} \times \boldsymbol{B}$ plasma drift, Ann. Geophys., 23, 371-378, 2005, http://www.ann-geophys.net/23/371/2005/.

Koustov, A. V., Drayton, R. A., Makarevich, R. A., McWilliams, K. A., St-Maurice, J.-P., Kikuchi, T., and Frey, H. U.: Observations of high-velocity SAPS-like flows with the King Salmon SuperDARN radar, Ann. Geophys., 24, 1591-1608, 2006, http://www.ann-geophys.net/24/1591/2006/.

Makarevich, R. A. and Dyson, P. L.: Dual HF radar study of the subauroral polarization stream, Ann. Geophys., 25, 2579-2591, 
2007, http://www.ann-geophys.net/25/2579/2007/.

Nishitani, N., Ogawa, T., and Kikuchi, T.: Hokkaido HF radar: progress report on mid-latitude latitude SuperDARN radar in East Asia, American Geophysical Union, Fall Meeting 2005, abstract \#SA23A-0300, 2005.

Nishitani, N., Ogawa, T., Kikuchi, T., Kataoka, R., Hosokawa, K., Yamagishi, H., and Yukimatu, A. S.: Initial observations with the Hokkaido radar, Paper presented at the Annual SuperDARN Workshop, 4-8 June, Abashiri, Hokkaido, Japan, 2007.

Oksavik, K., Greenwald, R. A., Ruohoniemi, J. M., Paxton, L. J., Baker, J. B. H., Gjerloev, J. W., and Barnes, R. J.: First observations of the temporal/spatial variation of the sub-auroral polarization stream from the SuperDARN Wallops HF radar, Geophys. Res. Lett., 33, L12104, doi:10.1029/2006GL026256, 2006.

Parkinson, M. L., Pinnock, M., Ye, H., Hairston, M. R., Devlin, J. C., Dyson, P. L., Morris, R. J., and Ponomarenko, P.: On the lifetime and extent of an auroral westward flow channel (AWFC) observed during a magnetospheric substorm, Ann. Geophys., 21, 893-913, 2003, http://www.ann-geophys.net/21/893/2003/.

Parkinson, M. L., Pinnock, M., Wild, J., Lester, M., Yeoman, T. K., Milan, S. E., Ye, H., Devlin, J. C., Frey, H. U., and Kikuchi, T.: Interhemispheric asymmetries in the occurrence of magnetically conjugate sub-auroral polarization streams, Ann. Geophys., 23, 1371-1390, 2005, http://www.ann-geophys.net/23/1371/2005/.

Parkinson, M. L., Wild, J. A., Waters, C. L., Lester, M., Lucek, E. A., and Décréau, P. M. E.: An auroral westward flow channel (AWFC) and its relationship to field-aligned current, ring current, and plasmapause location determined using multiple spacecraft observations, Ann. Geophys., 25, 59-76, 2007,

http://www.ann-geophys.net/25/59/2007/.
Ridley, A. J. and Liemohn, M. W.: A model-derived storm time asymmetric ring current driven electric field description, J. Geophys. Res., 107, 1151, doi:10.1029/2001JA000051, 2002.

Ruohoniemi, J. M. and Greenwald, R. A.: Rates of scattering occurrence in routine HF radar observations during solar cycle maximum, Radio Sci., 32, 1051-1070, 1997.

Starkov, G. V., Oksman, J., Uspensky, M. V., and Kustov, A. V.: On the dependence of radar aurora amplitude on ionospheric electron density, J. Geophys., 52, 49-52, 1983.

Tsyganenko, N. A.: Modeling the Earth's magnetospheric magnetic field confined within a realistic magnetopause, J. Geophys. Res., 100, 5599-5612, 1995.

Tsyganenko, N. A. and Stern, D. P.: A new-generation global magnetosphere field model, based on spacecraft magnetometer data, ISTP Newsl., 6(1), 21, 1996.

Weimer, D. R.: An improved model of ionospheric electric potentials including substorm perturbations and application to the Geospace Environment Modeling November 24, 1996 event, J. Geophys. Res., 106, 407-416, 2001.

Yeh, H. C., Foster, J. C., Rich, F. J., and Swider, W.: Storm time electric field penetration observed at mid-latitude, J. Geophys. Res., 96, 5707-5721, 1991. 